\title{
Persepsi Komunitas Adat Terpencil Suku Anak Dalam (SAD) terhadap Pelayanan Kesehatan
}

\author{
Mila Triana Sari ${ }^{1}$, Hartati Sandora ${ }^{2}$, Haflin ${ }^{3}$ \\ 1,2,3 Sekolah Tinggi Ilmu Kesehatan Baiturrahim Jambi, Indonesia \\ Correspondence email: milatrianasari273@yahoo.com
}

\begin{abstract}
Abstrak. Komunitas adat istiadat Suku Anak Dalam (SAD) adalah satu kelompok masyarakat yang hidupnya bergantung pada alam di hutan. Diperlukan usaha untuk memberikan layanan guna memenuhi kebutuhan mereka, terutama layanan perawatan kesehatan untuk meningkatkan kualitas hidup mereka. Penelitian ini dilakukan untuk mengetahui persepsi warga SAD terhadap Pelayanan Kesehatan di Wilayah Kerja Puskesmas Pematang Kabau. Penelitian ini dilakukan pada bulan Januari Februari 2017 untuk mendapatkan pemahaman persepsi masyarakat adat Suku Anak Dalam terhadap pelayanan kesehatan, jumlah partisipan adalah 11 orang Suku Anak Dalam dan 4 orang petugas kesehatan. Penelitian ini merupakan penelitian kualitatif dengan metode purposive sampling. Instrumen penelitian adalah wawancara mendalam dengan panduan wawancara, serta dianalisis dengan teknik Colaizzi.Temuan penelitian ini menunjukkan lima tema: alasan warga SAD dalam menerima pelayanan kesehatan, respon warga SAD terhadap pelayanan kesehatan, perubahan dan dampak warga SAD terhadap pelayanan kesehatan, makna pelayanan kesehatan bagi warga SAD, persepsi warga SAD terhadap pelayanan kesehatan. Warga SAD memberikan persepsi positif dan dukungan terhadap Pelayanan Kesehatan,petugas kesehatan perlu lebih efektif dalam menjalin komunikasi dengan warga SAD serta perlunya pemberdayaan kader dari warga SAD tersebut dalam membantu petugas kesehatan, serta menambah frekuensi kegiatan pusling sebagai pelayanan kesehatan tingkat pertama untuk menjangkau seluruh warga SAD dalam upaya peningkatan hidup sehat.
\end{abstract}

Kata kunci: Persepsi, Suku Anak Dalam (SAD) terhadap Pelayanan Kesehatan.

\begin{abstract}
The solitory custom community of Suku Anak Dalam (SAD) is one of group society whose life are depend to the natural researches in the forest. It is needed an effort to provide service in order to meet their needed, especially health care service for improving their quality of life in the solitary custom Community of Suku Anak Dalam. This research was conducted in order to know about the persepsion of SAD society towards Health Care Service in the Working Area of Puskesmas Pematang Kabau. This research was conducted on Januari until February 2017 for the purpose of getting understanding about persepsion of solitary custom Community of Suku Anak Dalam towards health care service, the number of participants were 15 people. This is qualitative research with purposive sampling method. The research instruments were indepth interview and interview guide. The result of the research analyzed by using Colaizzi Technique. The finding of the research showed five themes: the reason of SAD Society in terms of receiving care service. Secondly, the respond of SAD society, thirdly, about the changing and the impact of SAD society. Fourth, the meaning of health care service to SAD society. And fifth the experience of SAD society towards health and service.SAD society gave respond about perception or possitive support towards Health Care Service.
\end{abstract}

Keyword: Persepsion of Suku Anak Dalam (SAD) towards Health Care Service.

\section{PENDAHULUAN}

Orang Rimba atau yang dikenal dengan Suku Anak Dalam (SAD) merupakan salah satu etnik tradisional yang ada di Indonesia. Mereka bermukim di kawasan Taman Nasional Bukit Duabelas. Secara administrativ kawasan Taman Nasional Bukit Duabelas terletak di antara tiga Kabupaten yaitu Kabupaten Sarolangun Merangin, Tebo, dan Batang Hari. Tiga Kabupaten tersebut saling berbatasan di punggung perbukitan Bukit Duabelas. Kawasan yang di diami Orang Rimba ini secara geografis adalah kawasan yang di batasi oleh Batang Tabir di sebelah barat, Batang Tembesi di sebelah timur, Batang Hari di sebelah utara, dan Batang Merangin di sebelah selatan (Alam Sumatera, 2015).

Orang Rimba merupakan sebutan diri bagi komunitas adat terpencil yang hidup dan tersebar dalam hutan di Propinsi Jambi. Sebutan ini menurut mereka sebagai interpretasi dari kehidupan mereka yang sejak nenek moyangnya, menggantungkan hidupnya pada hutan dan hasil - hasilnya. Pemerintah menamai komunitas ini dengan sebutan yang berubah - ubah sesuai dengan proyek yang akan diberlakukan untuk komunitas ini. Diawali dengan sebutan suku terasing, yang merupakan generalisasi untuk semua suku yang di anggap "belum hidup normal". Kemudian mereka dinamai Komunitas Adat Terpencil, yang berikutnya disebut Suku Anak Dalam. Istilah Kubu merupakan sebutan yang dilekatkan oleh masyarakat Melayu pada komunitas ini. Kubu diartikan hidup liar, kotor, bau, penuh dengan kekuatan mistis, bodoh dan tertutup. Makanya penyebutan kubu ini sangat ditentang oleh Orang Rimba, dan kemudian mereka menyebutkan identitas mereka sebagai Orang Rimba atau Suku Anak Dalam. (Aritonang R, 2010).

Pemerintah melaksanakan berbagai program yang bermaksud untuk mengangkat derajat Suku Anak Dalam. Salah satunya PKAT ((Pemberdayaan Komunitas Adat Terpencil) yang bertujuan untuk memberdayakan komunitas adat terpencil dalam segala aspek kehidupan dan penghidupan agar mereka dapat hidup secara wajar baik jasmani, rohani, dan sosial sehingga dapat berperan aktif dalam pembangunan, yang pelaksanaannya dilakukan dengan memperhatikan adat istiadat setempat (Hendra Puja Anugrah, 2009).

Penguatan program tersebut dilakukan dengan pencanangan Presiden Republik Indonesia tentang program Kawasan Terpadu Mandiri Bagi Suku Anak Dalam yang bertujuan agar Komunitas SAD mendapatkan akses pelayanan kesehatan, sosial, 
maupun ekonomi. (Buletin Alam Sumatera, Desember 2015).

Selanjutnya Kementrian Kesehatan dalam Program Indonesia Sehat untuk mengatasi Masalah Kesehatan dengan menerapkan rencana strategis 20152019 antara lain: Penerapan Paradigma Sehat, Penguatan Pelayanan Kesehatan, dan Jaminan Kesehatan Nasional. Dalam Rangka Mendukung Kebijakan Pemerintah khususnya Penguatan Pelayanan Kesehatan yang lebih menyentuh terutama Komunitas Terpencil. Dinas Kesehatan Kabupaten Sarolangun melalui Puskesmas Pematang Kabau memberikan pelayanan kesehatan pada Komunitas Suku Anak Dalam yang berada di kawasan Taman Nasional Bukit Duabelas. (Dinkes Kab. Sarolangun 2015)

Pelayanan kesehatan bagi SAD bertujuan untuk agar SAD memahami pola hidup sehat, ancaman bahaya penyakit, pentingnya penyembuhan menggunakan obat dan memanfaatkan sarana pelayanan kesehatan.

Kehidupan SAD yang terpencil dan jauh dari fasilitas pelayanan kesehatan dan sarana transportasi yang terbatas, Sehingga perlu diteliti lebih mendalam makna dari pengalaman SAD terhadap pemanfaatan pelayanan kesehatan, sehingga dapat diketahui kebutuhan dan upaya yang perlu dilakukan pemangku kepentingan untuk meningkatkan derajat kesehatan SAD tersebut.

\section{METODE PENELITIAN}

Pendekatan yang digunakan dalam penelitian ini adalah kualitatif dengan metode fenomenologi. Metode fenomenologi merupakan suatu investigasi fenomena yang sangat mendalam, kritikal dan sistematik (Streubert \& Carpenter, 2003). Penelitian ini bertujuan untuk mengeksplorasi fenomena pengalaman komunitas adat terpencil Suku Anak Dalam terhadap pelayanan kesehatan yang dilaksanakan selama dua bulan, Januari sampai dengan Februari 2017. Penelitian ini dilakukan diwilayah kerja puskesmas pematang kabau kecamatan air hitam kabupaten sarolangun Jambi.dengan populasi SAD 706 jiwa dan partisipan 7 orang dengan tehnik pengambilan sampel purposive sampling, Informasi didapatkan melalui wawancara kelompok, wawancara mendalam serta observasi. Keabsahan data dilakukan dengan trangulasi sumber ataupun metode. Analisis data yang digunakan adalah Colaizzi Technique.

\section{HASIL DAN PEMBAHASAN}

Berikut ini dipaparkan mengenai karakteristik masing-masing partisipan (nama disamarkan dengan inisial), serta deskripsi hasil penelitian dari Persepsi Komunitas Adat Terpencil SAD Terhadap Pelayanan Kesehatan Di Wilayah Kerja Puskesmas Pematang Kabau Kecamatan Air Hitam Kabupaten Sarolangun Propinsi Jambi.

\section{Partisipan 1}

Partisipan 1 adalah Tn. T merupakan tokoh masyarakat (Temenggung) warga SAD berumur 70 Tahun, bermukim di pemukiman Air Panas Desa Bukit Suban Kecamatan Air Hitam Kabupaten Sarolangun Propinsi Jambi, beragama Islam, dan sudah menunaikan Ibadah Haji pada Tahun 2012 yang merupakan hadiah dari Pemerintah Kabupaten Sarolangun, karena peran nya sebagai pimpinan kelompok komunitas SAD dalam mendukung programprogram kebijakan pemerintah diataranya program kesehatan dan pelestarian kawasan Hutan Lindung Taman Nasional Bukit Duabelas. Disini partisipan banyak menjelaskan pengalamannya tentang pelayanan kesehatan dan manfaat yang sudah mereka rasakan, serta selalu memberikan motivasi bagi warganya untuk memanfaatkan fasilitas pelayanan kesehatan yang telah diberikan oleh Rajo (Sebutan Bagi Pimpinan Dalam Pemerintahan).

\section{Partisipan 2}

Partisipan 2 adalah Tn. G, laki-laki berumur 48 Tahun merupakan Pimpinan Warga SAD (Temenggung) di Pemukiman Bendungan Desa Bukit Suban Kecamatan Air Hitam Kabupaten Sarolangun Propinsi Jambi, belum memiliki agama atau menganut Animisme yang merupakan ajaran asli orang rimba, kehidupannya banyak dihabiskan di dalam rimba, memiliki 2 orang isteri yang hidup dalam satu rumah dengan damai. Setiap jadwal atau kesepakatan tentang pelayanan kesehatan yang telah ditentukan partisipan bersama warganya yang berada di dalam rimba dengan berbondong-bondong keluar dari rimba untuk mendapatkan pelayanan kesehatan di tempat yang sudah ditentukan yaitu Pendopo tempat mereka biasa berkumpul.

\section{Partisipan 3}

Partisipan 3 adalah Ny. I Perempuan berumur 65 Tahun, Isteri dari salah seorang Temenggung, beragama Islam, bermukim di Pemukiman Air Panas Desa Bukit Suban Kecamatan Air Hitam Kabupaten Sarolangun Propinsi Jambi, merpakan pemukiman yang bergabung berbagai Etnis atau suku diataranya ada dari suku jawa, batak, melayu jambi, mereka saling hidup rukun. Partisipan dengan keterbatasan komunikasi dengan dibantu informan dari Puskesmas Pematang Kabau menjawab satu persatu dari setiap pertanyaan peneliti tentang pengalaman pelayanan kesehatan.

\section{Partisipan 4}

Parsipan 4 adalah Tn. B laki-laki berumur 48 Tahun merupakan tokoh warga SAD yang bermukim di pemukiman SAD Ujung Kutai Desa Pematang Kabau Kecamatan Air Hitam Kabupaten Sarolangun Propinsi Jambi, beragama Islam, Partisipan belum lama menjadi Muallaf (Memeluk Agama Islam), dengan pengalaman hidupnya partisipan banyak menyampaikan tentang manfaat pelayanan kesehatan, partisipan dikenal cukup dekat dengan petugas kesehatan dari Puskesmas Pematang Kabau. Mempunyai 7 orang anak dari seorang isteri yang merupakan anak Temenggung, dan memiliki 4 orang cucu, dari 7 orang anaknya 2 diantaranya sedang belajar di SD dan TK (Kelompok belajar bagi warga SAD).

\section{Partisipan 5}

Partisipan 5 adalah An. B anak laki-laki berumur 12 Tahun warga SAD yang bermukim di pemukiman SAD Ujung Kutai Desa Pematang Kabau Kecamatan Air Hitam Kabupaten Sarolangun Propinsi Jambi, dan 
sedang belajar di Sekolah Dasar (Kelompok Belajar warga SAD) . Partisipan menjawab setiap pertanyaan dari peneliti tentang pengalaman terhadap pelayanan kesehatan dengan sangat lugu, walaupun terkadang sulit untuk dimengerti

\section{Partisipan 6}

Partisipan 6 dalam penelitian ini adalah Kepala Sub bagian Tata Usaha yang bertugas di Puskesmas Pematang Kabau yang selalu terlibat dalam menentukan kebijakan seluruh kegiatan Program Puskesmas, diantaranya Program Puskesmas Keliling (Pusling) Pelayanan Kesehatan Bergerak untuk Komunitas SAD. Informasi yang didapatkan dari pegawai Puskesmas ini adalah penjelasan tentang program kesehatan, terutama masalah penanganan kesehatan terhadap Komunitas SAD.

\section{Partisipan 7}

Partisipan 7 dalam penelitian ini adalah Perawat yang bertugas di Puskesmas Pematang Kabau yang selalu terlibat dalam kegiatan Puskesmas Keliling (Pusling) Pelayanan Kesehatan Bergerak untuk Komunitas SAD. Informasi yang didapatkan dari perawat akan memverivikasi ucapan atau penyampaian dari partisipan warga SAD mengenai pengalaman Komunitas Adat Terpencil SAD Terhadap Pelayanan Kesehatan.

Setelah data dianalisis, ditemukan lima tema besar sebagai berikut,

\section{Alasan warga SAD menerima Pelayanan Kesehatan}

Alasan adalah suatu proses penyimpulan dari data yang terdiri dari bukti (data), tuntutan (kesimpulan) dan pemikiran yang membenarkan gerakan dari data menuju ke kesimpulan. Dalam hal ini partisipan mengemukakan alasan utama menerima pelayanan kesehatan dengan penuh harapan. Alasan tersebut meliputi :

a. Kepuasan Terhadap Pelayanan kesehatan yang di sampaikan dalam pernyataan berikut ini :

"Perhatian pihak Puskesmas kepado kami baik nian,..........." (P1)

(Perhatian pihak Puskesmas Pematang Kabau Kepada Warga SAD baik sekali......) .........Kami jugo perlu kesehatan, ........" (P2)

(........Warga SAD juga memerlukan pelayanan untuk hidup sehat,.....)

“...........Awak biso berobat, ......." (P2)

(.......Warga SAD bisa mendapatkan Pelayanan Pengobatan....)

b. Manfaat pelayanan kesehatan yang dirasakan dalam pernyataan berikut ini :

" ........dengan kegiatan ibu iko awak biso tau penyebab penyakit kami” (P2)

(.....dengan kegiatan Pusling pada SAD , warga SAD dapat manfaat dari pelayanan kesehatan) .

".......kami biso sehat dikasih obat samo ibu,........" (P5)

(........ Warga SAD bisa sembuh dengan kegiatan Pusling SAD dari Puskesmas Pematang Kabau) .

c. Harapan Warga SAD dalam pernyataan berikut ini :

"Ibu datang ke sekolah iko kami senang....... biso berobat...." (P5)
(Komunitas SAD Sangat Mengharapkan Pelayanan Kesehatan) dengan wajah penuh harapan.

Komunitas Suku Anak Dalam (SAD) sudah mulai menyadari akan pentingnya untuk memenuhi kebutuhan hidup sehat, dengan perilaku hidup mereka dengan penuh keterbatasan sehingga sangat rentan dengan kesehatan mereka, secara perlahan warga SAD mengerti tentang manfaat dari pelayanan kesehatan yang mereka terima selama ini. Hal ini diidentifikasi dari beberapa pernyataan partisipan, seperti di ungkapkan partisipan 2, partisipan 3, dan partisipan 4. sementara partisipan 1, partisipan 5, partisipan 6 , dan partisipan 7 menyetujui jawaban dari ketiga partisipan sebelumnya.

Kepuasan personal yang diungkapkan oleh partisipan dalam proses pelayanan kesehatan yang dilakukan oleh petugas kesehatan baik secara personal maupun kelompok merupakan tolak ukur keberhasilan dalam pemberian pelayanan, sehingga mereka warga SAD bisa saling memberikan informasi positif kepada sesama warga SAD yang lain yang belum merasakan pelayanan kesehatan. Sehingga mereka bisa menentukan pilihan hidup yang lebih berkualitas seperti warga masyarakat modern yang selama ini mereka lihat.

Kualitas kesehatan dan pemanfaatan fasilitas pelayanan kesehatan meningkat. Masyarakat SAD kini berbaur dan membuka diri dengan masyarakat sekitar. Menurut Adi Prasetijo, 2010 mengatakan bahwa pilihan hidup ada yang datang dari keinginan sendiri Orang Rimba (SAD) untuk masuk ke arus global kehidupan disekitarnya. Meninggalkan identitas kerimbaanya dan beralih identitas sebagaimana masyarakat lainnya. Bagi yang memilih ini, sebagian ada yang sukses dengan pilihannya, namun sebagian justru terombang ambing dengan identitas diri yang kabur.

Untuk itu perlu upaya dan inovasi dari petugas kesehatan dalam melakukan pembinaan dan pelayanan kesehatan dengan pusling menggunakan mobil sehingga bisa menempuh lokasi terpencil dan pendekatan berdasarkan budaya suku anak dalam tersebut.

\section{Respon Warga SAD terhadap pelayanan kesehatan}

Respon warga SAD terhadap pelayanan kesehatan yang telah diberikan oleh Puskesmas Pematang Kabau meliputi jenis-jenis kegiatan pelayanan kesehatan yang diberikan yaitu : Pelayanan penyuluhan Kesehatan, Pemeriksaan Kesehatan, Pelayanan Imunisasi, Pelayanan KB, dan Pengobatan. Ketersediaan jenis pelayanan sesuai dengan respon warga SAD di tunjukkan dalam pernyataan sebagai berikut:

a. "......Kami jugo perlu kesehatan........" (P2) (Warga SAD juga membutuhkan pelayanan kesehatan yang sesuai dengan harapan dan kebutuhan mereka)

b. ".......Awak bawak kesiko anak-anak kalo ibu datang kesiko....." (P3)

(Warga SAD membawa anak-anak mereka ke tempat pelayanan kesehatan pada saat tim kesehatan datang )

c. "........Kami biso sehat dikasih obat samo ibu....." (P3) 
(Warga SAD bisa sembuh dari penyakit setelah diperiksa dan diberikan obat)

Kegiatan pelayanan kesehatan pada Komunitas SAD ditujukan untuk memenuhi kebutuhan dasar manusia. Berbagai macam perasaan yang muncul ketika memberikan pelayanan kesehatan pada komunitas SAD, baik dari petugas maupun warga SAD. Bagi petugas ini merupakan tantangan berat, karena faktor geografis kondisi jalan dan medan yang cukup berat untuk menuju lokasi pelayanan. Bagi warga SAD sendiri ini adalah hal yang cukup sulit, karena berbaur dengan orang luar, belajar mempercayai petugas kesehatan dan merubah prilaku pengobatan tradisional beralih ke obatobatan modern. Hasil wawancara menunjukkan pada umumnya SAD memberikan respon positif yaitu perasaan puas yang diungkapkan. Hal ini dapat dapat kita lihat dari pernyataan yang diungkapkan oleh partisipan 1, dan partisipan 2. Sementara partisipan 3, partisipan 4, partisipan 5, memberikan jawaban dengan menganggukkan kepala bertanda setuju atas jawaban dari kedua partisipan sebelumnya. Dan ini divalidasi dengan petugas kesehatan yang ada, menyatakan SAD dulunya pada bersembunyi ke hutan saat petugas kesehatan datang, sekarang sudah tidak bersembunyi lagi, mau berkumpul dan mau diperiksa kesehatannya.

\section{Perubahan dan dampak Komunitas Adat Terpencil (SAD) terhadap Pelayanan Kesehatan}

Perubahan sikap warga SAD terhadap pelayanan kesehatan yang telah diberikan oleh Puskesmas Pematang Kabau dan dampak yang dirasakan warga SAD di tunjukkan dalam pernyataan sebagai berikut

a. "............Kami jugo perlu kesehatan ........." (P2)

(Warga SAD juga membutuhkan pelayanan kesehatan yang merupakan bukti perubahan prilaku, atau sikap positif)

b. "........Awak bawak kesiko anak-anak kalo ibu datang kesiko....." (P3)

(Warga SAD membawa anak-anak mereka ke tempat pelayanan kesehatan pada saat tim kesehatan datang)

c. ".........Kami biso sehat dikasih obat samo ibu....." (P3)

(Warga SAD bisa sembuh dari penyakit setelah diperiksa dan diberikan obat)

Perubahan perilaku warga SAD yang sudah mendapatkan pelayanan kesehatan dari petugas kesehatan dapat dilihat seperti contoh, warga SAD yang sudah diperiksa dan mendapatkan obat dari petugas kesehatan maka mereka meminum obat secara teratur agar mereka cepat sembuh tanpa harus mencari ramuramuan di dalam rimba yang selama ini mereka lakukan sebelumnya. Perubahan perilaku yang dirasakan bagi mereka yang mendapatkan penyuluhan tentang perilaku hidup sehat, mandi dengan menggunakan sabun, melakukan gosok gigi, memeriksakan kehamilan, dan memberikan imunisasi pada bayinya.

Dampak yang dirasakan warga SAD dari pemberian pelayanan kesehatan yaitu kualitas hidup warga SAD yang lebih sehat, dibandingkan mereka yang belum mendapatkan pelayanan kesehatan. Hal ini dapat kita lihat dari pernyataan yang diungkapkan oleh partisipan 2, dan partisipan 3. Sementara partisipan 1, partisipan 4 , partisipan 5 , hanya memberikan jawaban dengan menganggukkan kepala bertanda setuju atas jawaban dari kedua partisipan sebelumnya.

\section{Makna Pelayanan Kesehatan bagi Warga SAD}

Makna pelayanan kesehatan yang telah diberikan pada warga SAD sangat berarti untuk kelangsungan hidup mereka di tunjukkan dalam pernyataan sebagai berikut:

a. "...........Awak senang ibu datang kesiko........"

(P2)

(Warga SAD gembira dengan kedatangan petugas kesehatan)

“........lbu ngobati kami....." (P4)

(Warga SAD mengerti akan makna pelayanan kesehatan)

b. ".........Kami biso sehat dikasih obat samo ibu....." (P3)

(Warga SAD bisa sembuh dari penyakit setelah diperiksa dan diberikan obat)

Pemberian pelayanan kesehatan bagi komunitas adat terpencil SAD berupaya untuk terjadinya perubahan sikap dan perilaku individu maupun kelompok SAD dalam kehidupannya, contoh perubahan sikap dalam menerima pelayanan yang diberikan oleh petugas, warga SAD bersedia datang ke tempat pelayanan dengan waktu yang telah disepakati. Perubahan sikap ini dapat kita lihat dari pernyataan partisipan 2, partisipan 3, dan partisipan 4. Sementara partisipan 1, partisipan 5, hanya memberikan jawaban dengan menganggukkan kepala bertanda setuju atas jawaban dari ketiga partisipan sebelumnya.

Menurut Sutardi dan Tri Arvian, 2010 mengatakan bahwa kendati cukup awas dengan datangnya penyakit, orang rimba juga tidak bisa terhindar sepenuhnya dari serangan penyakit. Karena itu, mereka juga memerlukan pengobatan (pelayanan kesehatan).

Pelayanan kesehatan yang telah diberikan pada warga SAD bukan hanya pengobatan saja, diantaranya dengan memberikan Penyuluhan tentang perilaku hidup sehat, agar supaya memberikan perubahan mendasar tentang perilaku warga SAD sebelumnya yang sama sekali belum mengetahui tentang perilaku hidup sehat.

\section{Persepsi Warga SAD terhadap Pelayanan Kesehatan}

Persepsi warga SAD terhadap pelayanan kesehatan di tunjukkan dalam pernyataan sebagai berikut:

a. "............Dengan kegiatan ibu iko kami jugo perlu kesehatan........" (P2)

(Warga SAD juga membutuhkan pelayanan kesehatan untuk memenuhi kebutuhan hidup sehat)

b. ".......Awak dan anak-anak biso berobat....." (P4)

(Seluruh Warga SAD mengerti akan makna pelayanan kesehatan)

c. ".........Kami terimo kasih nian samo ibu....." (P3)

(Warga SAD menyatakan terima kasih dengan pelayanan kesehatan yang telah di berikan)

Persepsi komunitas adat terpencil SAD terhadap pelayanan kesehatan yang telah dilakukan oleh petugas kesehatan selama ini, mereka bisa memberikan 
informasi positif kepada kerabat mereka yang lain tentang kesehatan, mereka sangat puas dalam menerima pelayanan kesehatan juga sangat berharap untuk kelanjutan kegiatan pelayanan kesehatan ini. Hal ini dapat dilihat dari ungkapan partisipan 2, partisipan 3, partisipan 4, dan partisipan 5. Sementara partisipan 1, hanya memberikan jawaban dengan menganggukkan kepala bertanda setuju atas jawaban dari keempat partisipan sebelumnya.

Hal ini sejalan dengan pendapat Sutardi dan Tri Arvian, 2010 yang mengatakan bahwa selain pelayanan kesehatan yang juga dibutuhkan orang rimba adalah pendidikan kesehatan. Ini berkaitan dengan persepsi tentang obat dan efek samping yang ditimbulkan, konsep tentang sehat sakit dan cara menghindari penyakit. Oleh karena itu perlu diberikan pendidikan kesehatan secara rutin dan dilakukan pengawasan terutama tentang pemakaian obat yang telah diberikan oleh petugas kesehatan.

\section{SIMPULAN}

Kesimpulan hasil Penelitian pada komunitas adat tepencil Suku Anak Dalam di wilayah kerja Puskesmas Pematang Kabau Kecamatan Air Hitam Kabupaten Sarolangun Propinsi Jambi terhadap pelayanan kesehatan dengan berbagai macam tema yang dirangkum dalam lima tema besar yang antara lain ; Alasan warga SAD menerima Pelayanan Kesehatan, Respon warga SAD terhadap pelayanan kesehatan, Perubahan dan dampak warga SAD terhadap pelayanan kesehatan, Makna pelayanan kesehatan bagi warga SAD, dan Pengalaman warga SAD terhadap pelayanan kesehatan.

Ketersediaan fasilitas dan tenaga kesehatan dalam memberikan pelayanan kesehatan yang sesuai dengan kebutuhan Komunitas Adat Terpencil Suku Anak Dalam merupakan faktor utama dalam meningkatkan pelayanan kesehatan, serta perlunya dukungan dari pemerintah dan sektor swasta terkait yang berada di sekitar Komunitas Adat Terpencil Suku Anak Dalam untuk lebih peduli terhadap kelangsungan hidup mereka.

Respon warga SAD berupa persepsi dan dukungan positif terhadap pelayanan kesehatan disampaikan dalam bentuk ungkapan rasa kepuasan dan hati senang, walaupun masih dirasakan masih banyak kekurangan dan keterbatasan dalam menerima pelayanan kesehatan, hal ini dikarenakan pola hidup komunitas SAD yang masih jauh ketinggalan dengan masyarakat modern lainnya.

Perubahan perilaku dan dampak yang di alami oleh Komunitas Adat Terpencil Suku Anak Dalam terhadap pelayanan kesehatan di wilayah kerja Puskesmas Pematang Kabau Kecamatan Air Hitam Kabupaten Sarolangun Propinsi Jambi sudah mulai dirasakan, antara lain secara bertahap masyarakat SAD sudah mulai mau berkunjung ke puskesmas bila sakit atau bila membutuhkan pelayanan kesehatan bagi diri dan keluarganya. Selain itu sinergi pemerintah pusat dan daerah semakin kuat dalam mewujudkan peningkatan kehidupan yang adil dan merata pada warga SAD.

\section{Saran}

1. Dinas Kesehatan Kabupaten Sarolangun.

Perlunya Dinas Kesehatan bersama dinas terkait untuk melakukan pendataan ulang seluruh warga SAD sehingga tidak ada keraguan bagi petugas kesehatan didalam memberikan pelayanan kesehatan baik di Faskes tingkat pertama (Puskesmas) dan Faskes lanjutan (Rumah Sakit), serta penataan pola hidup bagi kelangsungan kehidupan Komunitas SAD yang lebih berkualitas sehingga bisa terjamin kesehatannya.

2. Puskesmas Pematang Kabau

Perlu lebih ditingkatkan lagi pelayanan kesehatan, sehingga pelayanan kesehatan bisa dilaksanakan dapat secara menyeluruh dirasakan warga SAD.

3. Bagi Komunitas Adat Terpencil Suku Anak Dalam (SAD)

Agar dapat lebih meningkatkan pengetahuan tentang kesehatan dan menjalin hubungan komunikasi antara petugas kesehatan dengan komunitas SAD secara berkesinambungan diantaranya dibentuknya kader kesehatan dari warga SAD.

\section{DAFTAR PUSTAKA}

Adisasmita, 2007. Sistem Kesehatan. Ed.1 Penerbit PT Raja Grafindo Persada, Jakarta.

Adi Prasetijo, 2010. Orang Rimba Menantang Zaman Komunitas Konservasi Indonesia WARSI, Jakarta.

Alfajri, 2007. Journal, kearifan lokal Orang Rimba Taman Nasional Bukit Dua Belas,Skripsi Antropologi, Padang.

DC Aryadi, 2013. Journal Suku Anak Dalam (SAD) Di Jambi.

Dinkes, 2015. Data Laporan Pelayanan Kesehatan SAD Puskesmas, Dinas Kesehatan Kabupaten Sarolangun Propinsi Jambi.

2016. Data Laporan SAD/Dacil Puskesmas, Dinas Kesehatan Kabupaten Sarolangun Propinsi Jambi.

Firdaus, dkk,Profil Masyarakat Suku Anak Dalam (KUBU) di Kawasan Cagar Biosfir Bukit Dua Belas, WARSI, Jambi.

Ibrahim, Kehidupan Suku Anak Dalam Di Kecamatan Air Hitam Kabupaten Sarolangun. Journal Antologi Geografi Universitas Pendidikan Indonesia (2013)

Kemenkes RI, 2014. Permenkes No. 75 Tahun 2014, Tentang Puskesmas, Jakarta. 2015. Program Indonesia Sehat 2015-2019 Rencana Strategis Pembangunan Kesehatan. Jakarta.

KKI WARSI, Journal, Aritonang, Robert (et.al), 2010. Orang Rimba Menentang Zaman. Indonesia.

Moleong , 2007. Metodologi Penelitian Kualitatif. Ed. Rev. Penerbit PT Remaja Rosdakarya, Bandung.

Muntholib, 1995. Dalam Desertasinya berjudul Orang Rimbo

Notoatmodjo, 2007. Promosi Kesehatan dan IImu Perilaku. Penerbit Rineka Cipta, Jakarta.

Prasetijo, Adi, 2009. Journal Serah Jajah dan Perlawanan yang tersisa: Etnografi Orang Rimba di Jambi, Jakarta: Wedatama Widya Sastra.

Rakhmat, 2008. Alam Sumatera. Ed. 1/ tahun VII, Buletin Intern, WARSI ,Jambi 
Robert Aritonang, 2010. Orang Rimba Menantang Zaman, WARSI, Jambi.

R. Rangkuti dan Bubung A, 2010. Orang Rimba Menantang Zaman, WARSI, Jambi.

Saryono, 2011. Metodologi Penelitian Kualitatif, Yogyakarta: Nuha Medika

Saudagar, 2002. Pemberdayaan Model Entry Point Komunitas Adat Terpencil di Propinsi Jambi. Penerbit Bagian Proyek Dinas KSPM, Jambi.

Sifa Fauziah 692, 2013. Journal Suku Kubu Propinsi Jambi Pulau Sumatera.

Sunito S, 2008. Makalah Dalam Workshop "Ancaman Terhadap Etno- Ekologi Orang Rimba dari Hegemonika;italis dan Strategi Penyelamatannya". KKI - WARSI, Jambi.

Sutardi dan Tri Arvian, 2010. Orang Rimba Menantang Zaman - Komunitas Konservasi Indonesia WARSI, Jakarta.

Syaf R, 2006. Alam Sumatera. Ed. 1/tahun V. Buletin Intern, WARSI, Jambi. 2008. Survey Bio Region Kehidupan Orang Rimba. KKI -WARSI, Jambi.

Triono, 2005. Manajemen Puskesmas Berbasis Pradigma Sehat. Penerbit Sagung Seto, Jakarta. 